\title{
On the Inclusion of Toxic Potency in Product Fire Performance
}

\author{
RICHARD G. GANN \\ Building and Fire Research Laboratory \\ National Institute of Standards and Technology \\ 100 Bureau Drive \\ Gaithersburg, MD USA 20899-8664
}

\begin{abstract}
For fire hazard and risk assessment, it is not practical to expect to find toxic potency values for all potential combustibles, nor is it reasonable to expect the assessment to include precise values, even if they were available. In large part, this is due to the limited degree of established precision and accuracy of toxic potency estimates at the current state of the art. Nonetheless, smoke inhalation continues to be the leading cause of fire deaths. Thus, some expedited, but accurate construct for implementing smoke toxic potency data in a product's fire performance characterization is needed. This paper suggests that toxic potency values be grouped within factors of ten, and it is expected that most combustibles would be seen as "ordinary." An example of a process to estimate the grouping of toxic potencies is developed. This includes consideration of whether the objective of the hazard or risk assessment is to maintain the currently experienced level of toxic fire hazard or to decrease the general toxic hazard from the currently experienced level. Finally, worked examples of the process are provided.
\end{abstract}

KEYWORDS: hazard evaluation, product fire performance, risk assessment, smoke, toxicity

\section{INTRODUCTION}

The effect of product fire performance on occupant tenability during the course of a building fire, long the subject of research and professional dialog, has reached the stage where evaluation of concepts for pragmatic implementation of our knowledge is justifiable. There are framework documents for performance-based design, which provide the context for the use of information regarding the time that people can safely remain within a burning building [1]. From ISO TC92 SC3, Fire Threat to People and the Environment, there is a set of Standards and supporting documents that put smoke toxic potency and other tenability factors in perspective, describe how to measure them, and organize how to use the data [2]. Finally, there are numerous apparatus, being used or proposed (although not necessarily of known accuracy), for obtaining toxic potency data for combustible construction and furnishing products [3].

So, how are fire safety professionals to use such knowledge to improve (or even just sustain) a desired level of life safety in fires? Already, there are fire performance numbers associated with materials and, less frequently, finished products. (In this paper, a material refers to a relatively uniform solid substance, most commonly a polymer or blend of polymers, that may contain dispersed additives. Examples are a polyurethane foam and a cotton upholstery fabric. A finished product is a commercial entity, which may be composed predominantly of a single material, e.g., a wood bookshelf, or which may be an assembly of materials, e.g., an upholstered chair.) These fire performance numbers address such flammability indicators as ease of ignition and rate of heat release. To complement these, it would be valuable to have indicators of the potential contribution of finished products to the loss of tenability in a fire due to smoke inhalation.

It is probably not feasible to expect true and precise toxic potency measurements of all building and furnishing products. In their present state, true determinations involve the use of laboratory animals. Such tests are expensive to run, and there are insufficient laboratories to test the tens of thousands of products in the marketplace. In addition, concerns in some countries regarding routine animal testing makes unlikely the advent of regulations suitable for international trade. A number of test apparatus have been designed to measure the yields of known toxic gases [3], and there are empirical equations to use these yields to estimate the toxic potency of the combustion effluent [4,5]. Here again, the sheer number of finished products and the associated cost of testing makes it unlikely that universal testing would occur. 
Nonetheless, smoke inhalation continues to be the leading cause of fire deaths, at least in the United States [6]. Thus, some expedited, but accurate construct for implementing smoke toxic potency data in product fire performance characterization is needed.

The purpose of this paper is to stimulate such an effort. The paper presents a technically supported means of including smoke toxic potency in the description of a commercial construction or furnishing product. Such a description is needed for determining the effect of the total smoke from a fire on the ability of occupants to survive the fire. It must be emphasized that this paper is not a proposed regulatory scheme, but is an indicator of what the current and presumed technology allows.

Regulation of finished products based solely on a toxic potency value is not technically supportable. The threat to life safety in a fire depends on the layout of the building, the ventilation pattern, the nature and mobility of the occupants, any operable fire mitigation capability, flammability properties of the product (e.g., ease of ignition, rate of heat release), etc., in addition to the nature of the fire effluent.

In the following sections, there are a number of quantities and uncertainties that are estimated for the purpose of demonstrating the product characterization process. Some of these are derived from published data; others, such as the fractions in Scenario 2 under Objective 1, are examples. All should be revisited if this concept is to be developed further for fire safety practice.

\section{APPROACH}

\section{Precision and Accuracy of Smoke Toxic Potency Values}

Toxic potency values derived from the exposure of laboratory animals, generally rodents, typically are expressed as an $E C_{50}$, the smoke exposure that results in an effect $(E)$ on half of the animals. (The toxic potency of the effluent varies inversely with the $\mathrm{EC}_{50}$ value. Thus, a low $L C_{50}$ value indicates that it only takes a small exposure to result in death, and the effluent would be described as having a high toxic potency.) Virtually all published data are for lethality $\left(L C_{50}\right)$ and incapacitation $\left(I C_{50}\right)$ determined in bench-scale tests using small test specimens [7]. Most of the data are for 30 min exposures, followed by a 14-day post-exposure observation period. Indicative experimental uncertainties in these values are of the order of $\pm 30 \%$. Very little research has been conducted to determine the accuracy of such data relative to full-scale tests of the finished products from which the test specimens were abstracted. One such study estimated that, for the method that became NFPA 269 [8], the agreement was conservatively bounded by a factor of three [9].

An additional uncertainty lies in the extrapolation from the rodent to people. Carbon monoxide $\mathrm{LC}_{50}$ values for restrained rats are similar to those for people at rest [inferred from Reference 10], and if the smoke lethality is dominated by CO, then perhaps the rat value can be used as the people value. However, to the extent that other toxicants contribute to the potency, the scaling relationships are less well established.

Toxic potency values are also estimated from chemical analysis of the effluent from bench-scale combustion of test specimens $[4,5]$. The repeatability in toxicologically important yields among multiple tests of cuttings from the same finished product, conducted in the same laboratory, can be within $\pm 20 \%$ or less [11]. There are reasonable estimates of the exposures to narcotic gases (commonly CO and HCN) that result in the incapacitation of people, perhaps to within an uncertainty of $\pm 30 \%$ (inferred from Reference 10). The uncertainties in the incapacitating exposures to irritant gases are considerably larger and are the subject of current discussion within ISO TC92 SC3. The equations for estimating the effects of narcotic and irritant gases do not include all toxicants [4]. Thus, to the extent that additional toxicants contribute to the potency of the effluent, there may be an additional uncertainty in the predictive capability of the equations.

To date, no one has generated an organized set of data on which to base a relationship between the finished product and its individual component materials and their conformation within the product. It is a subject of current research to determine the extent to which the yields of toxic gases, emitted from a finished product burning at room-scale, are replicated by the yields of those gases from a test specimen cut from the product and combusted in a bench-scale apparatus. Thus, this paper has to presume that such data are available. 
It may appear that the state of this science is not yet ready to assign rigorous uncertainties to the effluent toxic potency values for people. However, it is consistent with the above discussion that toxic potency values that differ by an order of magnitude are likely to be truly different, and that is the characteristic that will be used in the following sections.

\section{Smoke Toxic Potency Values for Building Occupant Safety}

As noted above, most published toxic potency data indicate lethal hazard to the average rat for exposures of $30 \mathrm{~min}$. For most fire hazard and risk analyses, the premium is on providing safety from incapacitation of smoke-sensitive (s.s.) people for exposures of a few minutes. There is likely a variety of ways to obtain estimates for this purpose using the existing animal data. One method [12] incorporates previously published human susceptibility data, compiled in the determination of Acute Exposure Guideline Levels (AEGLs) for Hazardous Substances, level AEGL-2 [13]. This level is defined as "the airborne concentration of a substance at or above which it is predicted that the general population, including susceptible individuals, could experience serious, long-lasting effects or an impaired ability to escape" and is close to the meaning of incapacitation used in fire hazard and risk analysis. These data are combined with time-scaling derived from rat exposure data.

The outcome of this method [12] is that one-fifth of the rat $L C_{50}$ (30 min, 14-day post-exposure observation) is a reasonable estimate of the $I C_{50}(5 \mathrm{~min})$ for smoke-sensitive people. Determining an uncertainty in this multiplier was noted as difficult, but an estimate of $\pm 50 \%$ was given. Values obtained using this method are denoted in this paper as $I C_{50}$ ( 5 min, s.s. people) values.

The approach to estimating tenability in ISO 13571 separates the effects of narcotic gases, sensory irritants, heat, and smoke obscuration. Thus, there are effectively four $I C_{50}$ values to be considered. Since this paper addresses only toxic potency, the value to be used is the lower of the first two of these.

\section{Premises}

There are several additional premises on which the approach in this paper is founded.

1. Most life safety assessments will be for residential or office occupancies. Unlike, e.g., a chemical storage warehouse, only rarely will the combustibles in a life-threatening fire be dominated by a single product that produces highly unusual fire effluent.

2. Many combustible finished products are "ordinary" in chemical composition. That is, they are mainly composed of few types of common atoms, i.e., C, H, O, and N. To the extent that a finished product contains only these atoms, the important toxic combustion gases are few. A few products contain additional atoms, e.g., Si and S. Fire retardant additives typically contain atoms of the halogens, phosphorus, boron, and/or a few types of metals. To the extent that these additional atoms are present, there is potential for generation of additional toxic gases (or higher yields of some otherwise less prevalent toxic gases), such as those that result from incomplete combustion of the finished product.

3. We have indicators of the lethal toxic potency of the fire effluent from these "ordinary" products. Most are ordinary in value, with $L C_{50}$ (30 min, 14-day post-exposure observation) values averaging about $30 \mathrm{~g} / \mathrm{m}^{3}$ for well-ventilated flaming combustion [7], a value differing little from the potency predicted from $\mathrm{CO}$ and $\mathrm{CO}_{2}$ as the sole toxicants. The corresponding average $I C_{50}$ ( $5 \mathrm{~min}$, s.s. people) is $\approx 6 \mathrm{~g} / \mathrm{m}^{3}$. Based on the data in Reference 7 , the post-flashover $I C_{50}(5$ min, s.s. people) is $\approx 3 \mathrm{~g} / \mathrm{m}^{3}$. Note that this value will vary somewhat, depending on the degree of increased post-flashover $\mathrm{CO}$ generation for a given product or mix of products.

4. In hazard and risk analyses, the use of such simplifications as a global average toxic potency or a potency based on $\mathrm{CO}$ alone will miss those finished products whose more complex toxic potency is problematic.

5. In the early stage of a pre-flashover fire, the effluent from a single finished product can determine the toxic potency of the environment. In the later stages of a pre-flashover fire, vitiation likely gives toxic product yields closer to those from post-flashover fires, while the fire may still be limited to a single finished product. 
6. In a post-flashover fire, all involved products are burning simultaneously. The fire effluent is the sum of that produced by each of the combustibles present and burning. The consumed mass flux is high, and the smoke from incidental contributors (those with comparatively small mass present) is rarely important.

7. Incapacitation is a reasonable indicator of the loss of tenability in a burning building. Incapacitation is defined as the inability of a person to take action to effect his/her escape from danger to a place of safety. For inhaled smoke, this is dose-related for narcotic gases and concentration-related for irritant gases [4]. Another cause of incapacitation is pain from radiative and/or convective heat, while high visual obscuration can effectively incapacitate by eliminating constructive progress toward exits or places of refuge [4].

Given the broad uncertainty in the values of incapacitating toxic potency for people, there are four descriptors for the effluent from finished products:

Group 1: Distinctly less toxic effluent than that from typical combustibles in all types of fires. There should be few entries in this Group, since $\mathrm{CO}$ is almost always generated in the combustion.

Group 2: Regardless of toxic potency, the product is never a significant contributor to fire hazard due to the low mass present. An example is an on/off light switch plate.

Group 3: "Ordinary" contributor to the overall toxic potency, as characterized earlier.

Group 4: Significantly more toxic fire effluent than that from typical combustibles. The above discussion of uncertainty leads to grouping of these products in subgroups by factors of ten in toxic potency.

Finally, there are assumed to be two fire safety objectives:

1. Quantitation of the current level of toxic fire hazard, leading to maintenance of this level.

2. Decrease in the general toxic hazard from the currently experienced level.

\section{GROUPING PRODUCTS}

In the following, the above concepts, premises, and degree of precision are brought together to demonstrate how one might proceed with characterizing the potential contribution of finished products to toxic hazard in fires. Based on this characterization, which can vary by fire scenario, a product fits into one of the above four Groups.

The logic trails are such that a product described as fitting into Group 1 or Group 2 is not a significant contributor to a toxic threat to life safety. (Of course, such products with, e.g., a high mass burning rate can rapidly lead to an untenable thermal environment.) Products that are described as fitting into Group 3 (almost certainly the largest Group) are those products whose fire effluent characterizes the toxic hazard from the range of current conventional fires. Typically, products that are described as fitting into Group 4 will result in ordinary toxic hazard in some fire situations and will contribute to enhanced toxic hazard in others. Association with Group 4 is an alert to those performing fire hazard and risk analyses, rather than the basis for outright discrimination in product selection. The products may well have other characteristics that favor their use in some applications.

\section{Objective 1: Support Maintenance of the Current Level of Toxic Fire Hazard}

Scenario 1: Hazard dominated by a single burning product. This is characteristic of a stage of a preflashover fire.

Step 1. Estimate the human incapacitating toxic potency for the product by (a) measuring yields in a full-scale test or physical fire model, (b) by estimating the toxic potency based on measurement experience with similar products, or (c) by extrapolating the results of an animal exposure test to people. The potency estimation should include the effects of both narcotic and irritant toxicants. 
a. If the chemical formulation is "ordinary" and if the estimated toxic potency is significantly less than "ordinary," then the product fits in Group 1.

b. If the chemical formulation is "ordinary" and if the estimated toxic potency is also "ordinary," then the product fits in Group 3.

c. If the chemical formulation is "ordinary" and if the estimated toxic potency is one or more orders of magnitude above "ordinary," then the product fits in a subgroup of Group 4.

d. If there are elements in the chemical formulation that are known to generate potent byproducts, or if the toxic effects of compounds containing these elements are unknown, then further investigation is needed, almost certainly including an animal check test.

i. Negative findings from the further work would suggest that the product fits in Group 3.

ii. If the resulting toxic potency is one or more orders of magnitude higher than "ordinary," then the product fits in one of the Group 4 subgroups. If an animal check test is not practical, then the product might be fit into Group 4 as a default.

Step 2. Input the appropriate mean Group $I C_{50}$ value into the hazard or risk analysis.

Scenario 2: Hazard affected by multiple products. This is likely to be characteristic of a postflashover fire. For each product, do the following:

Step 1. Estimate the toxic potency for each product as in Scenario 1, Step 1 above.

Step 2. Identify whether the product is likely to be a significant ( $\geq 0.20$ mass fraction) contributor to the mass burning rate of the fire.

a. If so, estimate the contribution to the mass burning rate (mass fraction) to within about $20 \%$. If this is too difficult, estimate the product's fraction of the total combustible mass in the space.

b. For each significant contributor, divide its estimated mass fraction by its $I C_{50}$ and sum these (for use later). Faster burning products contribute more to the smoke, while the toxic potency of the smoke increases with decreasing $I C_{50}$ value.

c. The product grouping follows that of Scenario 1.

Step 3. Estimate the importance of each smaller contributor to the toxic hazard in the fire.

d. Estimate the maximum mass fraction of the contributor to any fire.

e. Divide this estimated mass fraction by its $I C_{50}$ and divide this quotient by the sum from Scenario 2, Step 2.b to obtain an impact ratio.

f. If the ratio is less than 0.1 , then the product fits in Group 3.

g. If the ratio is greater than 0.1 and especially if the estimated toxic potency is two or more orders of magnitude greater than "ordinary," then the product fits in Group 4.

If the results of these two processes lead to different results, the product fits in the higher number Group.

\section{Objective 2: Decrease Toxic Hazard from the Currently Experienced Level}

Step 1: Perform a hazard or risk analysis for the combustibles having the current "ordinary" toxic potency value. Choose the desired degree of hazard or risk reduction.

Step 2: Calculate a toxic potency value that provides this reduced level of toxic hazard. Keep in mind that fire hazard from heat exposure and limitation of egress by smoke obscuration are 
developing concurrently with the inhalation hazard. These represent the practical limit to decreasing the hazards from smoke inhalation. For the present analysis, it is assumed that the focus is on meaningful reduction of the contribution to human tenability of smoke of high toxic potency, and thus that toxic potency is the first characteristic of fire effluent to render a person incapacitated.

Step 3: Perform the estimations in the prior section (Objective 1), adjusting the reference value for "ordinary" toxic potency as indicated in Step 1 of this Objective.

Step 4: Designate the new Groups in some manner to distinguish them from those used in meeting Objective 1.

\section{EXAMPLE 1: ALTERNATIVE WALL PANELS}

In this example, there is a choice between using a type of wood paneling or a paneling made of a phenolic material. Assuming that the wood product is not fire-retarded, it is composed primarily of $\mathrm{C}, \mathrm{H}$, and $\mathrm{O}$ atoms, and is thus of "ordinary" chemical composition. Phenolics are also basically composed of $\mathrm{C}, \mathrm{H}$, and $\mathrm{O}$ atoms. However, this particular phenolic is flame retarded, with phosphorus atoms chemically bound within the polymeric structure.

\section{Pre-flashover Fire}

For a pre-flashover fire in which the wall lining is the primary combustible, Reference 7 indicates that the $L C_{50}$ for woods (rats, 30 min exposure plus 14-day post-exposure observation) is approximately $40 \mathrm{~g} / \mathrm{m}^{3}$, which is also "ordinary." Thus, this paneling would fit in Group 3. In performing the fire hazard or risk assessment, one would use the "ordinary" $I C_{50}\left(5 \mathrm{~min}\right.$, s.s. people) value of $6 \mathrm{~g} / \mathrm{m}^{3}$. (See the second premise above.)

Reference 7 refers to a phenolic resin with a rat $L C_{50}$ (30 min, 14-day post-exposure observation) of approximately $8 \mathrm{~g} / \mathrm{m}^{3}$. The document does not identify whether this resin contains phosphorus or not. Thus, this product under consideration would be examined further, as described under Scenario 1, Step 1.d of this paper. Since the toxic potency is already a factor of 4 higher than the "ordinary," and since the phosphorus-containing combustion products might be significant irritants, it is possible that this product would fit within Group 4.

\section{Post-flashover Fire}

For a post-flashover fire in which the room also contains pieces of upholstered furniture, assume that the wall covering fraction (by mass) is 0.3 of the flammable load and the furniture mass fraction is the remaining 0.7 . The post-flashover $I C_{50}\left(5 \mathrm{~min}\right.$, s.s. people) is about $3 \mathrm{~g} / \mathrm{m}^{3}$ for the wood paneling. The post-flashover $I C_{50}\left(5 \mathrm{~min}\right.$, s.s. people) value for the furniture is assumed to be about $2 \mathrm{~g} / \mathrm{m}^{3}$, which is in Group 3.

For the wood paneling, which also fits in Group 3, the sum of the (mass fraction/IC $\left.C_{50}\right)$ terms is $(0.3 / 3=0.1)$ $+(0.7 / 2=0.35) \approx 0.4$. Thus, the effluent from the furniture dominates the toxic potency of the effluent from this post-flashover room fire.

If the toxic potency of the post-flashover effluent from the burning phenolic panels were 10 times higher than that for the wood panels, the sum of the terms (mass fraction/I $\left.C_{50}\right)$ would be $(0.3 / 0.3=1)+(0.7 / 2=$ $0.35) \approx 1.4$. In this case, the factor of 10 difference in toxic potencies of the two products results in a nominal factor of 3 increase in overall effluent toxic potency. This suggests that the phenolic panel likely fits within Group 3.

For a situation in which the only burning item in some stage of the post-flashover fire were the wall panels, the toxic potency of the effluent from this phenolic paneling would be 10 times that for the wood paneling. The former would then fit within Group 4. 


\section{Overall Toxic Potency}

Since there is a difference in the nature of importance of the toxic potency of the phenolic wall paneling, depending on the fire scenario, it would fit in Group 4, the higher number Group. Here, the fire scenarios include instances where this product is the only combustible and one in which its contribution to the overall effluent toxic potency is reduced. These "bracket" the influence of the product, and further scenarios are not likely to generate different grouping for the product. This indicates that proper selection of the fire scenarios is important if the finished product can be used in a variety of applications.

\section{EXAMPLE 2: ALTERNATIVE OFFICE ACCESSORIES}

In this example, the combustibles are a set of stacked letter baskets. One set is made of wood, with an $I C_{50}\left(5 \mathrm{~min}\right.$, s.s. people) value of $6 \mathrm{~g} / \mathrm{m}^{3}$ for well-ventilated combustion [7] and $3 \mathrm{~g} / \mathrm{m}^{3}$ for underventilated combustion. The other is made of a modified acrylic, with an $I C_{50}$ (5 min, s.s. people) value of $1 \mathrm{~g} / \mathrm{m}^{3}$ for both combustion conditions. The total mass of the baskets is $0.6 \mathrm{~kg}$, about $0.2 \%$ of the summed mass of all the combustibles in the room. The other combustibles are all predominantly made of wood.

\section{Pre-flashover Fire}

If the fire were to start by the letter baskets, and if about one-third of the mass of the baskets burned before other items were ignited, then approximately $0.2 \mathrm{~kg}$ of effluent would be dispersed into the full volume of the office, assumed to be approximately $100 \mathrm{~m}^{3}$. The concentration of fire effluent would be $\approx 2 \mathrm{~g} / \mathrm{m}^{3}$. Given the uncertainties in toxic potency values, this concentration is comparable to the $I_{50}(5 \mathrm{~min}$, s.s. people) values for well-ventilated combustion for both products. This suggests that both products fit within Group 3.

\section{Post-flashover Fire}

For the wood baskets, which fit in Group 3, the sum of the (mass fraction $\left./ I C_{50}\right)$ terms is $(0.98 / 3=0.3)+$ $(0.02 / 3=0.007) \approx 0.3$. Thus, the effluent from the other furnishings dominates the toxic potency of the effluent from this post-flashover room fire. These baskets would fit in Group 2.

For the modacrylic baskets, the sum of the (mass fraction/IC $\left.C_{50}\right)$ terms is $(0.98 / 3=0.3)+(0.02 / 1=0.02) \approx$ 0.3. Thus, the effluent from the other furnishings again dominates the toxic potency of the effluent from this post-flashover room fire, and these baskets would also fit in Group 2.

If the toxic potency of the post-flashover effluent from the burning modacrylic baskets were 10 times higher than that for the wood baskets, the $I C_{50}(5 \mathrm{~min}$, s.s. people) value would suggest a fit in Group 4. However, the sum of the terms (mass fraction/IC 50 ) would be $(0.98 / 3=0.3)+(0.02 / 0.3=0.007) \approx 0.3$. Thus, the effluent from the other furnishings still dominates the toxic potency of the effluent from this postflashover room fire, and these baskets would still fit in Group 2.

\section{Overall Toxic Potency}

Since, in a normal occupancy, there is unlikely to be a sufficient mass of this type of product to affect the toxic potency of the effluent from an office fire, a fit within Group 2 is appropriate. In this manner, a large number of incidental products can be disregarded in performing a toxic hazard analysis.

\section{GENERAL NOTES}

There is a large variation in the sophistication of the methods that could be used to perform a fire hazard analysis. There are also different ways in which smoke toxicity information could be included. For instance, if one chose to represent the toxic potency of the smoke as derived from the yields of a set of toxic gases from a burning item, one could use (a) the changing yields of toxic gases as the combustion progressed from well ventilated to underventilated conditions, (b) a set of yield values averaged over the entire burn time, or (c) a set of conservative (most hazardous) yields, i.e., those from the underventilated stage. Any of these approaches could have merit in fire reconstruction or in specialized cases of designed facilities. This paper suggests that, for general design of facilities, universal testing of products for smoke 
toxic potency is unlikely and that consideration be given to placing finished products into groups according to their potential contributions to toxic fire hazard.

The reader should perceive that there is a coarseness in the characterization of toxic potency values and thus the grouping of finished products. This is a direct result of the limited precision and accuracy of the toxic potency data, as currently obtained. (See the Approach section.) Making product selection decisions or performing hazard analyses at a higher degree of discrimination (based on, e.g., more significant figures in the toxic potency values) is unwarranted at today's state of toxic potency measurement.

The totality of burning products determines the overall smoke composition. Thus, a given product may be in different groups, depending on what else is burning in a particular fire scenario. Since one cannot presume the mix of finished products that will participate in a fire, the characterization of a particular product is that of the highest numbered group (in the sample approach in this paper).

\section{ADDITIONAL CONSIDERATIONS}

There are other factors that can significantly affect the contribution of a finished product to the overall toxic potency of the fire effluent. These fall into three categories.

1. Factors that affect the timing of the contribution of the product to the fire. This includes significant delay in ignition of the product or a mass burning rate that differs significantly from the rates of involvement of other burning products.

2. Factors that affect the mode of burning of the product. For example, a product whose ignition is prevented would contribute to the effluent by oxidative (or non-oxidative) pyrolysis. The gases generated might be quite different from those from flaming combustion and could result in very different toxic potency values, as can be seen for some of the materials in Reference 7.

3. Factors that limit the burning of the product altogether, such as the placement of the product behind a protective barrier that is not penetrated prior to the fire and is not damaged by the fire.

These factors need to be included in the hazard or risk analysis, rather than in the grouping of finished products.

\section{DISCLAIMER}

This paper is a contribution of the National Institute of Standards and Technology and is not subject to copyright in the United States.

\section{ACKNOWLEDGEMENTS}

The concept for this paper was triggered by discussions at a number of fire safety meetings, notably those of ISO TC92 SC3, Fire Threat to People and the Environment. Discussions of what was termed "Enlightened Toxic Hazard" (with one focus being on defining when one did not need to perform tests with laboratory animals) arose from a Fire Protection Research Foundation session. The people involved, in addition to the author of this paper, were Fred Clarke, Tom Fritz, John Hall, Gordon Hartzell, and Paul Hough. Finally, a reminder that this was still an open issue came from a conversation with Craig Beyler at Interflam 2007.

\section{REFERENCES}

[1] Mowrer, F.W., Overview of Performance-based Fire Protection Design, Fire Protection Handbook $\left(19^{\text {th }}\right.$ ed), Cote, A.E. (ed.), National Fire Protection Association, Quincy, MA 02269, 2003, Chapter 14.

[2] As of January 2008, the suite of ISO TC92 SC3 documents consists of nine Standards and one Technical Report. Those directly applicable to this paper are cited below. The philosophy for this suite of documents is described in ISO 19706-2007, Guidelines for Methodology for Assessing the Fire Hazard to People, International Standards Organization, Geneva. 
[3] ISO 16312-1-2006, Guidance for Assessing the Validity of Physical Fire Models for Obtaining Fire Effluent Toxicity Data for Fire Hazard and Risk Assessment - Part 1: Criteria, and ISO/TR 16312-2-2007, Part 2: Evaluation of Individual Physical Fire Models, International Standards Organization, Geneva.

[4] ISO 13571-2007, Life-threatening Components of Fire - Guidelines for the Estimation of Time Available for Escape Using Fire Data, International Standards Organization, Geneva.

[5] ISO 13344-2004, Estimation of the Lethal Toxic Potency of Fire Effluents, International Standards Organization, Geneva.

[6] Gann, R.G., Babrauskas, V., Peacock, R.D., and Hall, Jr., J.R. (1994), Fire Conditions for Smoke Toxicity Measurement, Fire and Materials 18: 193-199, http://dx.doi.org/10.1002/fam.810180306.

[7] Neviaser, J.L., and Gann, R.G., (2004) Evaluation of Toxic Potency Values for Smoke from Products and Materials, Fire Technology, 40: 177-200, http://dx.doi.org/10.1023/B:FIRE.0000016842.67144.12.

[8] NFPA 269-2007, Standard test Method for Developing Toxic Potency Data for Use in Fire Hazard Modeling, National Fire Protection Association, Quincy, MA 02269.

[9] Babrauskas, V., Levin, B.C., Gann, R.G., Paabo, M., Harris, Jr., R.H., Peacock, R.D., and Yusa, S., Toxic Potency Measurement for Fire Hazard Analysis, National Institute of Standards and Technology Special Publication 827, Gaithersburg, MD, 1991, 107 p.

[10] Purser, D.A., "Toxicity Assessment of Combustion Products." The SFPE Handbook of Fire Protection Engineering ( $3^{\text {rd }}$ ed), DiNenno P.J. (ed.), National Fire Protection Association, Quincy, MA 02269, 1995, Chapter 2-6.

[11] Unpublished NIST data from the NFPA 269 radiant apparatus.

[12] Gann, R.G., (2004) Estimating Data for Incapacitation of People by Fire Smoke, Fire Technology, 40: 201-207, http://dx.doi.org/10.1023/B:FIRE.0000016843.38848.37.

[13] Standing Operating Procedures for Developing Acute Exposure Guideline Levels for Hazardous Chemicals, National Academy Press, Washington, DC 20418, 2001. 
